\title{
A proposed model representing the relationships between user characteristics, computer exposure and musculoskeletal symptoms in children ${ }^{1}$
}

\author{
C.Harris ${ }^{\mathrm{a}, \mathrm{b}}$, L.Straker ${ }^{\mathrm{b}}$, A. Smith ${ }^{\mathrm{b}}$ and C. Pollock ${ }^{\mathrm{c}}$ \\ ${ }^{a}$ School of Occupational Therapy and Social Work, Curtin University, Perth, WA 6845, Australia. \\ ${ }^{\mathrm{b}}$ School of Physiotherapy, Curtin University, Perth, WA 6845, Australia \\ 'School of Psychology and Speech Pathology, Curtin University, Perth, WA 6845, Australia
}

\begin{abstract}
Children's computer exposure is rapidly growing. Several studies have suggested children using computers may be at risk of developing musculoskeletal symptoms. General models and theories relating to the causality of negative musculoskeletal outcomes in adult workers demonstrated relationships between workplace factors and musculoskeletal outcomes. When examining children's computer exposure it is evident that their use is different. Even though risk factors may be similar, due to the nature of children and their computer environments, the potential risk factors and thus a proposed model of causal relationships between exposure and outcomes may differ. Objective: To develop a model of factors influencing computer exposure and musculoskeletal symptoms in children. Methods: 1351 children (or their parents for Year 1 children) in school Years 1, 6, 9 and 11 (ages $\sim 6,11,14,16$ years) from 10 schools in Western Australia were surveyed on a range of user characteristics, computer exposure and musculoskeletal symptoms. Results: Potential risk factors for childrens' computer exposure and musculoskeletal outcomes were multivariable. Factors such as age, gender, somatic complaints, flow, computer anxiety, computer, TV and physical activity exposure, and SES were related to computer exposure and children's reports of musculoskeletal symptoms. Significance: Developing a child-related computer exposure model to understand relationships between potential risk factors and musculoskeletal symptoms will assist academics, teachers and parents to develop a better understanding of the risk factors for children's computer exposure.
\end{abstract}

Keywords: children, computers, ergonomics, models, musculoskeletal outcomes

\section{Defining the issue}

\subsection{Children's computer exposure}

Today in western societies, information technology (IT) plays a central role in children's lives ${ }^{[32]}$. Marshall et al. (2006) ${ }^{[25]}$, in their systematic review of adolescent computer exposure covering 90 international studies across 539 independent samples (1985 - 2004), report findings that children are likely to use IT such as television (TV), computers and electronic games for $25 \%$ of their waking hours. Lap- tops, mobile phones, handheld electronic games, in addition to TVs, are now considered to be indispensible by many families ${ }^{[19]}$.

Computer use in particular has been found to be an important type of IT with children using desktop and laptop computers to play games, write documents, complete learning programs, work with pictures and music in multimedia programs, surf the internet and communicate by email and chat rooms $^{[34]}$.

Computer use by children is growing rapidly ${ }^{[31]}$. With increasing access to computers and the internet at both school and home, the proportion of children

\footnotetext{
${ }^{1}$ Dr Courtenay Harris. C.harris@curtin.edu.au.
} 
using computers and their daily exposures have reportedly increased ${ }^{[4,31]}$.

\subsection{Relationships between children's computer ex- posure and environment and user factors}

Current literature demonstrates that children's computer exposure is influenced by a range of factors including environment factors of access, location and socio-economic status (SES); and user factors such as age, gender, psychological attributes and general activity participation.

In regards to environment factors, children use computers in a variety of environments, particularly at school ${ }^{[20,28]}$ and home ${ }^{[5,18,20,28]}$. Nearly all children in affluent communities use computers at school and the majority use computers at home ${ }^{[3,36]}$. Recent literature demonstrates some common trends for greater school and home computer access for children from high SES areas, but greater general computer exposure for children from low SES areas ${ }^{[7,32]}$.

In regards to user factors, age / school year level are related to computer exposure, with most studies reporting an increase in exposure with age ${ }^{[20,28,31,32]}$.

Many studies indicate that boys are more likely to have greater exposure to computers than girls $[20,28]$. However as in Chou and Tsai's (2007) study, children's computer exposure was often targeted at gaming activities only, which traditionally has been shown to be used more by boys than girls ${ }^{[8,20,28,29]}$.

Recent literature indicates that increased body mass index (BMI) and obesity in children may be linked to sedentary behaviors such as computer exposure ${ }^{[28]}$. Additionally concerns that computer exposure displaces moderate vigorous physical activity (MVPA) have been raised ${ }^{[24]}$.

Psychological attributes associated with children's computer exposure include somatic complaints, computer anxiety and sustained attention. An increase in somatic complaints and computer exposure have been seen in a large representative child sample ${ }^{[30]}$. Computer anxiety has been shown to be negatively related to children's computer exposure ${ }^{[2,21]}$, whereas a positive relationship between children's flow experience (sustained attention) and computer exposure has been demonstrated ${ }^{[2]}$.

Recent literature suggests that heavy users of one type of IT are often heavy users of other types ${ }^{[5,31,32]}$. Furthermore, children have often been found to 'multi-task', using multiple IT simultaneously ${ }^{[31,32]}$.

\subsection{Relationships between children's computer exposure and outcomes}

The impact of children's computer exposure has reportedly been both positive and negative ${ }^{[8,32,34]}$. Positive effects associated with computer exposure discussed include increased socialization ${ }^{[20,29,]}$; enhanced cognitive development (improved learning and academic skills) ${ }^{[5]}$; and enhanced physical development (improved fine motor / eye hand coordination skills) $^{[37]}$.

Negative effects associated with computer exposure reportedly include; poor psychological development (aggressive behavior, violence, addiction, depression, attention deficits, somatic wellbeing) ${ }^{[15] \text {; }}$ poor physical development (reduced activity levels, obesity and musculoskeletal outcomes) ${ }^{[16,28]}$ and general health issues (sleep disturbance and reduced nutrition) ${ }^{[10]}$.

Recent studies reporting musculoskeletal outcomes associated with children's computer exposure have identified risk factors such as frequency, duration and prolonged periods of uninterrupted use $[14,16,18]$

\subsection{Relationships between musculoskeletal outcomes and user factors}

Research also demonstrates that user factors, as previously discussed in relation to children's computer exposure, are associated with children's reports of musculoskeletal discomfort. The prevalence of children's musculoskeletal outcomes is reported to increase with age ${ }^{[1,22]}$. Findings on the relationship between gender and the prevalence of general musculoskeletal outcomes in young people have been mixed. Some studies report a higher prevalence forfemales ${ }^{[1,22]}$, however other studies have found either no gender differences with prevalence only ${ }^{[35]}$, or higher reports for boys ${ }^{[6]}$. Consistent findings for a relationship between female gender and musculoskeletal outcomes are reported for the prevalence of recurrent and continuous symptoms, and the impact attributed to the outcomes ${ }^{[1,35]}$.

\subsection{Adult related risk factors and models asso- ciated with computer exposure.}

The etiology of IT related musculoskeletal outcomes have often been defined by adult's work related computer exposure. Potential adult related risk factors identified as being associated with muscu- 
loskeletal outcomes are multidimensional. For example: individual factors (eg. genetics, age, gender, anthropometry, psychosocial profile, cognition, physiology); physical environment and biomechanical factors (eg. force, posture, movement and vibration) and task demands / work organization (eg. repetitive paced tasks) ${ }^{[1,23,26,27]}$.

Furthermore, models have been developed that attempt to represent the relationships between exposure to risk factors and precipitation of musculoskeletal outcomes ${ }^{[1,23,26]}$. Although varied, these models show that musculoskeletal outcomes are linked to the interaction of a number of risk factors, and it is thought that musculoskeletal outcomes can follow a dose - response relationship ${ }^{[1]}$. Most of these models suggest that musculoskeletal outcomes cannot be fully explained through physical causes alone, and that psychological, social and environmental factors will also influence the precipitation of musculoskeletal outcomes ${ }^{[23,26]}$.

As previously argued ${ }^{[17]}$ when comparing potential risk factors for adults versus children, and even though many risk factors may be similar, due to the nature of children and their environments, it is proposed that potential risk factors and models of causal relationships between computer exposure and musculoskeletal outcomes would be different for children.

This paper discusses findings from a study aimed to develop a model of the multidimensional relationships between children's user characteristics, computer exposure and musculoskeletal outcomes.

\section{Method}

The study design involved a large cross-sectional survey of 1351 students (792 boys and 559 girls) from eight primary and five secondary in Perth, Australia. A survey tool, rather than observations and time diaries, was used within this study to allow for a large sample of data to be collected. Data was collected during the months of August to November, 2006.

Students were recruited, via stratified sampling methods. Schools were firstly selected based on neighbourhood SES (NSES) categories, to ensure a range of children from different SES backgrounds were represented in the study. As selected schools within those SES categories agreed to participate, certain year levels and genders were then targeted to represent both genders and ages of $6-17$ years.

The survey tool used with this study was based on the Young People's Activity Questionnaire
(YAQ) ${ }^{[16]}$ with the addition of extra questions regarding other activity types and computer activities at school and home. This YAQ-II was completed by children in school Years 6, 9 and 11, with a simplified version (Year One's Activity QuestionnaireYOAQ), being completed by Year 1 parents.

Both questionnaires contained questions relating to the participant and their activity exposure as an individual, within a family context, and within their neighbourhood. Questions and measurement scales used throughout the questionnaires measured the study's independent and dependent variables. Data collected was used to develop a model to identify potential risk factors associated with children's computer related musculoskeletal outcomes.

Descriptive statistics, frequency analysis and Spearman rank correlation coefficients $\left(r_{s}\right)$ were used to describe the sample, exposure related outcomes, and to examine the direction and strength of bivariate relationships between characteristics. Wilcoxon Signed Rank tests (W), Kruskal-Wallis tests (H), McNemar Tests $\left(x^{2}\right)$, Mann-Whitney U-tests (U), Spearman Rank Correlation Coefficients $\left(\mathrm{r}_{\mathrm{s}}\right)$ and Chi squared $\left(x^{2}\right)$ analysis were used to examine the relationships between computer exposure, user characteristics and outcome measures. SPSS v17 was used for these analyses. These non-parametric statistical methods were used due to the non-normality of the measures. These statistics provided preliminary findings, which together with current literature defined the proposed model as discussed in Section 3 of this paper.

This study was approved by the Curtin University Human Research Ethics committee.

\section{Results}

The following results section discusses the study's preliminary findings on relationships between user characteristics and computer exposure; relationships between computer exposure and musculoskeletal soreness (MSS); and relationships between user characteristics and musculoskeletal soreness.

\subsection{Relationship between user characteristics and computer exposure}

\subsubsection{Relationships between Year level and gender and computer exposure}

Frequency of school and home computer exposure over the last month was associated with Year level ( $\left.\operatorname{school} x_{(12)}^{2}=91.3, \mathrm{p}<.001\right)$ (home $x_{(12)}^{2}=261.4$, 
$\mathrm{p}<.001)$ and gender $\left(\operatorname{school} x^{2}{ }_{(4)}=12.5, \mathrm{p}=.014\right)$ (home $x^{2}{ }_{(4)}=5.3, \mathrm{p}=.004$ ), with frequency of computer use increasing with Year level and boys.

Duration of school and home computer exposure over the last month was associated with Year level for usual duration ( $\operatorname{school} x^{2}{ }_{(8)}=102.8, \mathrm{p}<.001$; home $\left.x^{2}{ }_{(12)}=163.2, \mathrm{p}<.001\right)$ and longest duration (school $x^{2}{ }_{(8)}=60.5, \mathrm{p}<.001 ;$ home $\left.x_{(12)}^{2}=102.8, \mathrm{p}<.001\right)$, and gender for school longest duration only $\left(x^{2}{ }_{(4)}=16.9\right.$, $\mathrm{p}=.002)$, and home usual duration $\left(x^{2}{ }_{(4)}=15.3\right.$, $\mathrm{p}=.004)$ and longest duration $\left(x_{(4)}^{2}=25.6, \mathrm{p}<.001\right)$. Increased school and home computer exposure for duration was evident with increasing Year level and for boys.

\subsubsection{Relationships between somatic complaints and computer exposure}

Somatic complaints surveyed included reports of headache and stomach pain. Frequency of headaches was positively related to computer weekly hours (school $\mathrm{r}_{\mathrm{s}}=.072, \mathrm{p}=.017$; home $\mathrm{r}_{\mathrm{s}}=.157, \mathrm{p}<.001$ ), frequency (school $r_{s}=.061, p=.038$; home $r_{s}=.125$, $\mathrm{p}<.001$ ), usual duration (school $\mathrm{r}_{\mathrm{s}}=.088, \mathrm{p}=.003$; home $\mathrm{r}_{\mathrm{s}}=.145, \mathrm{p}<.001$ ), and longest duration (school $\mathrm{r}_{\mathrm{s}}=.091, \mathrm{p}=.003$; home $\mathrm{r}_{\mathrm{s}}=.115, \mathrm{p}<.001$ ), indicating that participants with a higher frequency of headaches had greater exposure to computers.

Stomach pain was not associated with school computer exposure. However, frequency of stomach pain was positively related to home computer weekly hours $\left(\mathrm{r}_{\mathrm{s}}=.086, \mathrm{p}=.006\right)$, frequency $\left(\mathrm{r}_{\mathrm{s}}=.071, \mathrm{p}=.016\right)$, usual duration $\left(\mathrm{r}_{\mathrm{s}}=.067, \mathrm{p}=.026\right)$ and longest durations $\left(\mathrm{r}_{\mathrm{s}}=.085, \mathrm{p}=.005\right)$, indicating that participants with a higher frequency of stomach pain had greater exposure to home computers.

\subsubsection{Relationships between flow and anxiety and computer exposure}

School and home computer flow were related to

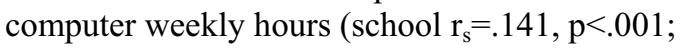

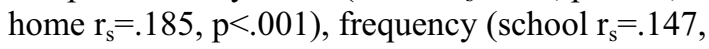
$\mathrm{p}<.001$; home $\mathrm{r}_{\mathrm{s}}=.180, \mathrm{p}<.001$ ), usual duration (school $\mathrm{r}_{\mathrm{s}}=.069, \mathrm{p}=.020$; home $\mathrm{r}_{\mathrm{s}}=.178, \mathrm{p}<.001$ ) and longest duration (school $r_{s}=.073, p=.014$; home $r_{s}$ $=.222, \mathrm{p}<.001$ ). Participants with more flow had greater computer exposure. Computer anxiety was negatively related to school computer frequency $\left(r_{s}=-\right.$ $.082, \mathrm{p}=.005$ ) only, indicating that participants with greater computer anxiety used school computers less frequently. Computer anxiety was also related to home computer weekly hours $\left(\mathrm{r}_{\mathrm{s}}=-.184, \mathrm{p}<.001\right)$, frequency $\left(\mathrm{r}_{\mathrm{s}}=-.222, \mathrm{p}<.001\right)$, usual duration $\left(\mathrm{r}_{\mathrm{s}}=\right.$ $.118, \mathrm{p}<.001)$, and longest durations $\left(\mathrm{r}_{\mathrm{s}}=-.199\right.$, $\mathrm{p}<=.001$ ), indicating that participants with greater computer anxiety had reduced home computer exposure.

\subsubsection{Relationships between television (TV) and computer exposure}

Frequency of watching TV was positively correlated to school and home computer exposure (school: $\mathrm{r}_{\mathrm{s}}=.079, \mathrm{p}<.001$; home: $\mathrm{r}_{\mathrm{s}}=.166, \mathrm{p}<.001$ ). Usual duration of TV was positively correlated to school and home computer usual duration (school: $\mathrm{r}_{\mathrm{s}}=.131$, $\mathrm{p}<.001$; home: $\mathrm{r}_{\mathrm{s}}=.334, \mathrm{p}<.001$ ), and longest durations (school: $\mathrm{r}_{\mathrm{s}}=.195, \mathrm{p}<.001$; home: $\mathrm{r}_{\mathrm{s}}=.339$, $\mathrm{p}<.001$ ). Weekly hours of computer use was positively correlated to TV usual durations (school: $\mathrm{r}_{\mathrm{s}}=.101$, $\mathrm{p}<.001$; home: $\left.\mathrm{r}_{\mathrm{s}}=.251, \mathrm{p}<.001\right)$.

\subsubsection{Relationships between MVPA exposure and computer exposure}

MVPA frequency was positively associated with school computer frequency $\left(\mathrm{r}_{\mathrm{s}}=.060, \mathrm{p}=.031\right)$ and negatively associated with home computer durations (usual $\mathrm{r}_{\mathrm{s}}=-.088, \mathrm{p}=.002$; longest $\mathrm{r}_{\mathrm{s}}=-.056, \mathrm{p}=.047$ ) and mean weekly hours $\left(\mathrm{r}_{\mathrm{s}}=-.075, \mathrm{p}=.010\right)$. Participants with greater frequency of MVPA were more likely to have greater frequency of school computer exposure and reduced duration of home computer exposure.

MVPA of usual and longest duration showed similar patterns in relation to school and home computer exposures. These results show that participants with greater durations of MVPA were more likely to have greater durations of school and home computer exposure.

\subsubsection{Relationships between neighbourhood socioe- conomic status (NSES) and computer exposure}

NSES was positively related to school computer mean weekly hours $\left(\mathrm{r}_{\mathrm{s}}=.086, \mathrm{p}=.004\right)$, frequency $\left(\mathrm{r}_{\mathrm{s}}=.148, \mathrm{p}<.001\right)$ and longest durations $\left(\mathrm{r}_{\mathrm{s}}=.088\right.$, $\mathrm{p}=.003$ ), indicating that participants from an area of high SES advantage were more likely to use computers at school for more hours, more frequently and for longer durations. Conversely, home computer use was negatively related with NSES for home computer weekly hours $\left(\mathrm{r}_{\mathrm{s}}=-.157, \mathrm{p}<.001\right)$, usual duration $\left(\mathrm{r}_{\mathrm{s}}=-.220, \mathrm{p}<.001\right)$ and longest duration $\left(\mathrm{r}_{\mathrm{s}}=-.138\right.$, $\mathrm{p}<.001$ ), indicating that participants from an area of SES disadvantage were more likely to use computers at home for more hours and for longer durations. 


\subsection{Relationship between computer exposure and musculoskeletal soreness (MSS)}

$10.1 \%$ of participants reported experiencing MSS at least monthly with school computer use and $20.7 \%$ of participants at least monthly with home computer use. Table 1 shows the frequency of MSS with school and home computer exposure.

Table 1 Percentage (n) of participants reporting musculoskeletal soreness with school and home computer exposure

\begin{tabular}{lcclc}
\hline \multicolumn{4}{c}{ Frequency of Musculoskeletal Soreness } \\
\hline $\begin{array}{l}\text { Activity } \\
\text { type }\end{array}$ & Monthly & Weekly & $\begin{array}{l}2-3 \mathrm{x} \\
\text { week }\end{array}$ & Daily \\
\hline $\begin{array}{l}\text { School } \\
\text { computer }\end{array}$ & $5.6(65)$ & $3.2(37)$ & $0.5(6)$ & $0.8(9)$ \\
$\begin{array}{l}\text { Home } \\
\text { computer }\end{array}$ & $9.9(113)$ & $6.1(70)$ & $3.2(37)$ & $\begin{array}{l}1.5 \\
(17)\end{array}$ \\
\hline
\end{tabular}

Frequency of school computer related MSS was associated with school computer frequency $\left(\mathrm{r}_{\mathrm{s}}=.110\right.$, $\mathrm{p}>001$ ), indicating a greater frequency of MSS with greater frequency of school computer. Frequency of home computer related MSS was associated with school computer frequency $\left(\mathrm{r}_{\mathrm{s}}=.091, \mathrm{p}>001\right)$, and all home computer exposure measures (frequency: $r_{s}=.150, p>001$; usual duration: $r_{s}=.110, p>001$; longest duration: $\left.r_{s}=129, p>001\right)$, indicating a greater frequency of soreness with greater home computer exposure.

\subsection{Relationship between user characteristics and musculoskeletal soreness}

\subsubsection{Relationships between age and gender and musculoskeletal soreness}

Frequency of computer related MSS was positively correlated with age for home computer use $\left(\mathrm{r}_{\mathrm{s}}=.111, \mathrm{p}<.001\right)$, but not school computer use $\left(\mathrm{r}_{\mathrm{s}}\right.$ $=.044, \mathrm{p}=.140)$. A greater frequency of computer related MSS was associated with girls than boys (school: $x_{(4)}^{2}=9.4, p=.051$; home: $x_{(4)}^{2}=25.1, \mathrm{p}<.001$ ).

\subsubsection{Relationships between somatic and musculoske- letal soreness \\ Frequency of computer related MSS was posi- tively related to frequency of headaches (school $\mathrm{r}_{\mathrm{s}}=.129, \mathrm{p}>.001$; home: $\left.\mathrm{r}_{\mathrm{s}}=.182, \mathrm{p}>.001\right)$ and stomach pain $\left(\right.$ school $_{\mathrm{s}}=.180, \mathrm{p}>.001$; home: $\mathrm{r}_{\mathrm{s}}=.207$, $\mathrm{p}>.001)$.}

\subsubsection{Relationships between flow and anxiety and NSES and musculoskeletal soreness}

Frequency of school and home computer related MSS were not associated with school or home computer flow. Frequency of school and home computer related MSS were not associated with computer anxiety. Frequency of school $\left(\mathrm{r}_{\mathrm{s}}=-.016, \mathrm{p}=.598\right)$ and home $\left(\mathrm{r}_{\mathrm{s}}=-.013, \mathrm{p}=.668\right)$ computer related MSS was not associated with NSES.

\section{Discussion}

\subsection{Proposed model variables}

Correlates have been included in the proposed model (see Figure 1) due to evidence from the literature and / or preliminary findings reported above.

\subsubsection{User correlates}

Age and gender in this study, as in recent literature, have been found to be related to the amount and nature of computer exposure, with an increase in exposure and different exposure patterns depending on gender $^{[8,20,25,31,32]}$. Age and gender were also found to interact in their association with reports of computer related musculoskeletal outcomes, with older females more likely to report outcomes. Age and gender were thus included in the model.

Recent literature indicates that increased BMI and obesity in children may be linked to sedentary behaviors such as computer exposure ${ }^{[28]}$. Whilst these factors were not assessed in this study, evidence suggests that they are an important factor and so BMI was included in the proposed model.

Recent literature has shown the continued prevalence of $T V$ watching in children's lives ${ }^{[31]}$. Additionally, heavy users of one type of IT have been found to be heavy users of other IT ${ }^{[32]}$. TV watching was found within this study to have moderate correlations with the school and home computer exposure. TV exposure was therefore included in the model.

Previous literature has reported concerns with computer exposure displacing $M V P A^{[24]}$. Preliminary analysis within this study demonstrated mixed findings, with negative and positive correlations existing depending on the measures of frequency or duration of exposure used. Given this, MVPA was included in the model.

Somatic complaints (headache and stomach pain) within recent literature have been used as measures of children's psychological health ${ }^{[15]}$. Additionally, their role in influencing musculoskeletal symptoms has been shown in recent literature ${ }^{[9]}$. Somatic complaints within this study have been 
shown to be related to increased computer exposure and computer related musculoskeletal outcomes and were therefore included in the model.

Computer anxiety has been reported to be associated with computer exposure ${ }^{[2,33]}$ and this study has demonstrated similar findings with participants demonstrating reduced exposure with more anxiety. Computer anxiety was thus included in the model. Children's sustained attention (flow) has been reported to be positively associated with computer exposure ${ }^{[2]}$. Within this study flow was associated with both school and home computer exposure. Flow was therefore included in the model. Literature has shown a digital divide in access to computers for children ${ }^{[7,32]}$. Within this study, NSES was associated with the amount and nature of school and home computer exposure. NSES was thus included in the proposed model.

\subsubsection{Computer exposure variable}

Previous child related literature has shown evidence for the use of exposure measures of frequency and duration to define children's computer exposure $[14,16,18]$.

Additionally, computer related musculoskeletal outcomes have been shown when using computers more frequently and for longer durations ${ }^{[16,18]}$. Therefore, frequency and duration as measures for computer exposure are both important for characterizing risks associated with computer exposure ${ }^{[12]}$. As exposure literature has recommended the use of more than one estimate for an exposure profile ${ }^{[13]}$ and as frequency and duration were found to both be clearly important to describe computer exposure patterns in the current study, a parsimonious solution for the proposed model would be to use a combined outcome measure.

\subsubsection{Musculoskeletal soreness variable}

Previous literature has used the single outcome measure of frequency of soreness as an outcome measure ${ }^{[14]}$. This study's preliminary analysis showed that frequency of musculoskeletal soreness was the most consistent measure of a range of outcome variables used within the study. For this reason musculoskeletal soreness frequency was recommended for the proposed model.

\subsection{Proposed model}

The proposed model, as illustrated in Figure 1, includes the model variables of user characteristics, computer exposure and musculoskeletal soreness.
Direct and indirect pathways are illustrated on the model. These pathways illustrate the relationships between user characteristics and computer exposure and/ or musculoskeletal soreness as demonstrated through recent literature and/ or the study preliminary findings.

Pathways indicated by a dashed arrow show characteristics hypothesized to have a direct effect on computer exposure and therefore an indirect effect on musculoskeletal soreness. Pathways indicated by a solid arrow show characteristics hypothesized to have had a direct effect on musculoskeletal soreness.

\subsubsection{Adult vs child specific model}

This study's proposed child related model has both similarities and differences to adult theories. Similar to adult theories, the proposed child model has a multivariate approach and demonstrates relationships between correlates both external (eg. SES, computer environment, other activities participation, computer exposure) and internal (eg. Age, gender, computer anxiety, somatic complaints, flow) to the child user ${ }^{[23,26,27]}$.

Many adult theories however are related to general work environments. As the current study's focus was specifically computer exposure, exposure and musculoskeletal outcomes were specifically computer related. This is also similar to Sauter and Swanson's (1996) ${ }^{[27]}$, Ecological model of musculoskeletal disorders in adult visual display terminal users. "Work" tasks for both involve computer exposure, and have also both included similar user characteristics (inputs), including psychological, individual factors, work organization and somatic complaints. The cognitive component of this adult model referring to the detection and attribution of symptoms, has also been shown to be important in this study's child specific model. Differences between the models however are related to the types of computer environment and physical biomechanical factors included within the model. Due to children's school and home computer exposure and varying SES backgrounds family and computer environments were represented in the current study's model. Additionally, this adult model shows the potential injury mechanisms as demonstrated by biomechanical components of physical demands and biomechanical strains. The current child related study was not able to measure these physical and biomechanical aspects of exposure due to the study design and constraints of a large scale survey.

Similar to adult theories and models is that this child related model proposes pathways to demon- 
strate directions for the relationships between variables, and imply both direct and indirect effects of risk factors on musculoskeletal outcomes. These pathways should be assessed in further research.

\subsection{Strengths and limitations}

Limitations of the study were primarily related to the cross sectional study design, self report for exposure and outcome estimates with limited evidence of psychometric properties of some aspects. Strengths of the study included a large representative sample of children from across a range of ages, including both genders and a range of SES backgrounds. The large sample allows for future multivariable path analysis and modeling to be performed.

\subsection{Conclusion}

In conclusion, this study's proposed child specific model shows relationships between user characteristics, children's computer exposure and musculoskeletal outcomes. This model proposes that child computer users are different from adult computer users in work environments, and thus reflect the unique characteristics of children, their computer environments and musculoskeletal outcomes. These findings will assist researchers, teachers and parents to understand the range of potential risk factors for children's computer related musculoskeletal outcomes. This will also allow researchers to target interventions to child users and their computer environments to ensure children's computer use is performed in a safe and productive manner.

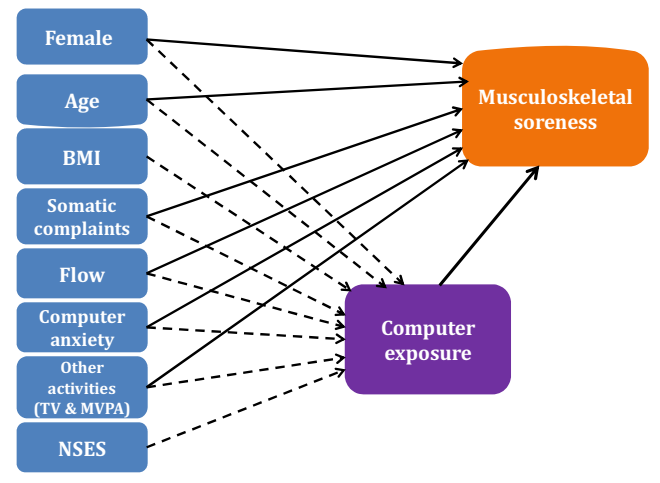

Figure 1: Modified proposed pathway model of the direct and indirect relationships between user characteristics, computer exposure and related musculoskeletal soreness

\section{References}

[1] T. Armstrong, B. Buckle, L. Fine, M. Hagberg, B. Jonsson, A Kilbom, I. Kourinka, B. Silverstein, and ER. Viikari-Juntura, A conceptual model of work-related neck and upper-limb musculoskeletal disorders. Scandinavian Journal of Work Environment Health, 19 (1993), 73-84.

[2] K. Arrowsmith, The occurence of flow in Year 6 children's use of computers. Unpublished thesis Degree of Bachelor of Science with Honours (Psychology). Curtin University of Technology, 2002.

[3] Australian Bureau of Statistics (ABS), Information paper: An introduction to socio-economic indexes for SEIFA. Available at http://www.abs.gov.au/Ausstats/abs. Accessed April 21, 2007.

[4] Australian Bureau of Statistics (ABS). Household use of information technology, 2008 - 2009. Canberra. http://www.abs.gov.au/Ausstats/abs@.nsf/0/A4A719717D5B3 59BCA2575220013CF6B?OpenDocument. Accessed November 10, 2010.

[5] D. Borzekowski, and T. Robinson, The remote, the mouse, and the no. 2 pencil. Archives of Pediatrics and Adolescent Medicine, 159 (2005), 607-613.

[6] A. K. Burton, R. D. Clarke, T.D. McClune, and K. Tillotson, The natural history of low back pain in adolescents. Spine, 20 (1996), 2323 - 2328.

[7] S. Calvert, V. Rideout, J. Woodland, R. Barr, and G. Strouse, Age, ethnicity, and socio-economic patterns in early computer use. The American Behavioral Scientist, 48 (2005), (5), 590607.

[8] C. Chou and M-J. Tsai, Gender differnces in Taiwan high school students' computer game playing. Computers in Human Behaviour, 23 (2007), 812-824.

[9] G. Crombez, K. Beirens, S. Van Damme, C. Eccleston, and J. Fontaine, The unbearable lightness of somatisation: A systematic review of the concept of somatisation in empirical studies of pain. Pain, 145 (2009), 31-35.

[10]M. Dworak, T. Schierl, T. Bruns and H.K. Struder, Impact of singular excessive computer game and television exposure on sleep patterns and memory performance of school-aged children. Pediatrics, 120 (2007), (5), 978-985.

[11]A. El-Metwally, J. Salminen, A. Auvinen, G. Macfarlane, and M. Mikkelsson, Risk factors for development of non-specific musculoskeletal pain in preteens and early adolescents: a prospective 1-year follow-up study. BMC Musculoskeletal Disorders, 8 (2007), (1), 46.

[12]R. Gillespie, The physical impact of computers and electronic game use on children and adolescents, a review of current literature. Work, 18 (2002), 249 - 259.

[13] M. Hagberg, Exposure variables in ergonomic epidemiology. American Journal of Industrial Medicine, 21 (1991), 91-100.

[14]P. Hakala, A. Rimpela, L. Saarni, and J. Salminen, Frequent computer-related activities increase the risk of neck-shoulder and low back pain in adolescents. European Journal of Public Health, 16 (2006), 536.

[15]M. Hamer, E. Stamatakis, and G. Mishra, Psychological distress, television viewing, and physical activity in children. Pediatrics, 123 (2009), 1263-1268.

[16]C. Harris, and L. Straker, Survey of the physical ergonomics issues associated with school children's use of laptop computers. International Journal of Industrial Ergonomics, 26 (2000), 337-346.

[17]C. Harris and L. Straker, Musculo-skeletal outcomes in children using computers - the need for a specific etiological mod- 
el. International Journal of Industrial Ergonomics, 35 (2005), 131-138.

[18]K. Jacobs, S. Hudak, and J. McGiffert, Computer-related posture and discomfort in middle school students. Work, 32(2009), 275-283

[19]A. Kappos, The impact of electronic media on mental and somatic children's health. International Journal of Hygiene and Environmental Health, 210 (2007), 555-562.

[20]N. Kent and K. Facer, Different worlds? A comparison of young people's home and school ICT use. Journal of Computer Assisted Learning, 20 (2004), 440-455.

[21] J. King, T. Bond, and S. Blandford, An investigation of computer anxiety by gender and grade. Computers in Human Behavior, 18(2002), 69-84.

[22] G. Kristjánsdóttir, Prevalence of pain combinations and overall pain: A study of headache, stomach pain and back pain among school-children. Scandinavian Journal of Social Medicine, 25 (1997), 58 - 63.

[23] S. Kumar, Theories of musculoskeletal injury causation. Ergonomics, 44 (2001), 17-47.

[24] S. Marshall, S. Biddle, T. Gorely, N. Cameron, and I. Murdey, Relationships between media use, body fatness and physical activity in children and youth: a meta-analysis. International Journal of Obesity and Related Metabolic Disorders 28 (2004), 1238-1246.

[25] S. Marshall, T. Gorely, and S. Biddle, A descriptive epidemiology of screen-based media use in youth: A review and critique. Journal of Adolescence, 29 (2006), 333-349.

[26] S.E. Mathiassen, Variation in shoulder-neck activtity. Physiological, psychological and methodological studies of isometric exercise and light assembly work. Stockholm, Sweden: National Institute of Occupational Health, 1993.

[27] S. Moon, and S. Sauter, Beyond biomechanics: Psychological aspects of musculoskeletal disorders on office work. London: Taylor \& Francis, 1996.

[28]T. Olds, K. Ridley, and J. Dollman, Screenieboppers and extreme screenies: the place of screen time in the time budgets of 10-13 year old Australian children. Australian and New Zealand Journal of Public Health, 30 (2006), 137-142.

[29] M. Orleans, and M. Laney, Children's computer use in the home: Isolation or Sociation? Social Science Computer Review, 18 (2000), 56-72.

[30]R-L. Punamaki, M. Wallenius, C-H, Nygard, L. Saarni, and A. Rimpela, Use of information and communication technology (ICT) and perceived health in adolescence: The role of sleeping habits and waking-tiredness. Journal of Adolescence, 30 (2007), 569-585.

[31] V. Rideout, U. Foehr, and D. Roberts, Generation M2: Media in the lives of 8 to 18 year olds. California, USA: A Kaiser Family Foundation Study. (\#8010). Retrieved from www.kff.org. 2010.

[32]D. Roberts, U. Foehr, and V. Rideout, Generation M: Media in the Lives of $8-18$ Year Olds. California, USA: Kaiser Family Foundation. Retrieved from www.kff.org. September 12, 2008, 2005

[33]E. Rozell, and W. Gardner, Computer-related success and failure: A longitudinal field study of the factors influencing computer-related performance. Computers in Human Behavior, 15 (1999), 1-10.

[34]L. Straker, B. Maslen, R. Burgess-Limerick, P. Johnson, and J. Dennerlein, Evidence-based guidelines for the wise use of computers by children: Physical development guidelines. Ergonomics, 53(2010), 458-477.

[35] S.Taimela, U.M. Kujala, J.J. Salminen, and T Viljanen, The prevalence of low back pain among children and adolescents. A nationwide, cohort-based questionnaire survey in Finland. Spine, 22 (1997), 1132 - 1136.

[36]US Census Bureau (UCB). The 2008 Statistical Abstract, Information and Communicatons. http://www.census.gov/compendia/statab/2008/cats/informatio n communications.html, 2008.

[37] H. Yuji, Computer games and information - processing skills. Perceptual and Motor Skills 83 (1996), 643-647. 